\title{
NOX2 Inhibition Impairs Early Muscle Gene Expression Induced by a Single Exercise Bout
}

\section{Carlos Henríquez-Olguín ${ }^{1,2}$, Alexis Díaz-Vegas ${ }^{1}$, Yildy Utreras-Mendoza ${ }^{1}$, Cristian Campos ${ }^{1}$, Manuel Arias-Calderón ${ }^{1}$, Paola Llanos ${ }^{3}$, Ariel Contreras-Ferrat ${ }^{4}$, Alejandra Espinosa ${ }^{4}$, Francisco Altamirano ${ }^{1}$, Enrique Jaimovich ${ }^{1}$ and Denisse M. Valladares ${ }^{1 *}$}

${ }^{1}$ Facultad de Medicina, Centro de Estudios Moleculares de la Célula, Instituto de Ciencias Biomédicas, Universidad de Chile, Santiago, Chile, ${ }^{2}$ Laboratory of Exercise Sciences, Clínica MEDS, Santiago, Chile, ${ }^{3}$ Facultad de Odontología, Institute for Research in Dental Sciences, Universidad de Chile, Santiago, Chile, ${ }^{4}$ Facultad de Medicina, School of Medical Technology, Universidad de Chile, Santiago, Chile

Reactive oxygen species (ROS) participate as signaling molecules in response to exercise in skeletal muscle. However, the source of ROS and the molecular mechanisms involved in these phenomena are still not completely understood. The aim of this work was to study the role of skeletal muscle NADPH oxidase isoform 2 (NOX2) in the molecular response to physical exercise in skeletal muscle. BALB/c mice, pre-treated with a NOX2 inhibitor, apocynin, $(3 \mathrm{mg} / \mathrm{kg})$ or vehicle for 3 days, were swim-exercised for $60 \mathrm{~min}$. Phospho-p47 ${ }^{\text {phox }}$ levels were significantly upregulated by exercise in flexor digitorum brevis (FDB). Moreover, exercise significantly increased NOX2 complex assembly (p47 ${ }^{\text {phox }}$-gp91 $1^{\text {phox }}$ interaction) demonstrated by both proximity ligation assay and co-immunoprecipitation. Exercise-induced NOX2 activation was completely inhibited by apocynin treatment. As expected, exercise increased the mRNA levels of manganese superoxide dismutase (MnSOD), glutathione peroxidase (GPx), citrate synthase (CS), mitochondrial transcription factor A (tfam) and interleukin-6 (IL-16) in FDB muscles. Moreover, the apocynin treatment was associated to a reduced activation of p38 MAP kinase, ERK 1/2, and NF-kB signaling pathways after a single bout of exercise. Additionally, the increase in plasma IL-6 elicited by exercise was decreased in apocynin-treated mice compared with the exercised vehicle-group $(p<0.001)$. These results were corroborated using gp91-dstat in an in vitro exercise model. In conclusion, NOX2 inhibition by both apocynin and gp91dstat, alters the intracellular signaling to exercise and electrical stimuli in skeletal muscle, suggesting that NOX2 plays a critical role in molecular response to an acute exercise.

Keywords: redox signaling, antioxidant defense, reactive oxygen species, IL-6, NADPH oxidase, muscle adaptation

\section{INTRODUCTION}

It is well known that regular exercise induces several beneficial effects in skeletal muscle, such as an increased insulin sensitivity (Kirwan et al., 2009), mitochondrial biogenesis (Hood et al., 2015), and endogenous antioxidant defense (Ristow et al., 2009). Multiple signaling pathways have been implicated in exercise-promoted skeletal muscle health, nonetheless the precise mechanisms 
involved in these effects are not fully understood (Neufer et al., 2015).

During the past decade, a large body of evidence demonstrated that reactive oxygen species (ROS) generation is upregulated during exercise in several tissues (Jackson, 2011). Exerciseinduced ROS production acts as a signal to activate redox sensitive pathways that result in activation of transcription factors and gene expression, modulating both acute response and long-term training adaptation (Strobel et al., 2011). Moreover, training increases the expression of antioxidant enzymes as superoxide dismutase (SOD), glutathione peroxidase (GPx), and catalase (Ristow et al., 2009). It has been reported that ROS also participate in exercise-induced mitochondrial adaptation (Piantadosi and Suliman, 2012), such as increased expression and activity of citrate synthase (CS) (Strobel et al., 2011). Interestingly, ROS scavengers can impair early or long-term effects of exercise including antioxidant gene expression and mitochondrial biogenesis (Ristow et al., 2009; Petersen et al., 2012; Paulsen et al., 2014b; Qi et al., 2014).

The production of ROS has long been recognized as a critical component of skeletal muscle physiology, but the sites that generate superoxide and hydrogen peroxide during exercise have remained controversial (Jackson, 2016). Mitochondria have been traditionally considered as the major ROS source in skeletal muscle (Powers et al., 2011). However, recent studies have reported that during short periods of contraction, a rise in cytosolic ROS precedes and is greater than the increase in mitochondrial ROS generation (Pearson et al., 2014; Sakellariou et al., 2014), suggesting that non-mitochondrial ROS generation could be the major ROS source in skeletal muscle. Accordingly, xanthine oxidase (XO; Gomez-Cabrera et al., 2005) and NADPH oxidase (NOXs) emerge as possible candidates to participate in the redox-dependent skeletal muscle plasticity (Sakellariou et al., 2014) but the former appears not to have an important role in muscle adaptation (Wadley et al., 2013).

The NOXs are protein complexes that generate ROS in a highly regulated manner in response to cytokine, hormonal, and mechanical signals (Lambeth, 2004). NAPDH oxidase isoform 2 (NOX2) is expressed in skeletal muscles and it is composed of both catalytic and regulatory subunits (Espinosa et al., 2016). The gp91 phox and p22 $2^{\text {phox }}$ subunits are localized mainly in the sarcolemma and transverse tubules, whereas the regulatory components: $\mathrm{p} 47^{\text {phox }}, \mathrm{p} 67^{\text {phox }}, \mathrm{p} 40^{\text {phox }}$, and Rac1 are present in the cytoplasm (Hidalgo et al., 2006). Upon stimulation, the cytosolic subunits translocate to the membrane and full enzyme assembly takes place, accompanied by enzyme activation and ROS generation (Lambeth, 2004). The highly specific localizations and activation of NOX2 in skeletal muscle represent a high potential for spatial and temporal regulation of redox signaling in skeletal muscle physiology. However, the role of NOX2 in exercise-induced ROS signaling remains largely unknown.

The exercise-induced multi-systemic adaptation are mediated partially by the secretion of myokines from skeletal muscle (Pedersen and Febbraio, 2012). During the past years, IL-6 has emerged as an important cytokine to coordinate metabolic functions during and after exercise. This cytokine is produced and released into the bloodstream in response to muscle contraction (Keller et al., 2005). The molecular mechanism involved in exercise-induced IL-6 expression is still unclear, even though it has been suggested that ROS-regulated transcription factors participate in the signaling (Scheele et al., 2009). Supporting this hypothesis, we recently showed that electrical stimulation is able to increase IL-6 expression through activation of both NOX2 and of NF- $\mathrm{KB}$ transcriptional activity in skeletal muscle cells (Henríquez-Olguín et al., 2015).

The aim of this work was to study the contribution of NOX2 activation to intracellular signaling in response to a single bout of exercise in skeletal muscle. We hypothesize that exerciseinduced NOX2 activation modulates early responses related with antioxidant and metabolic signaling in skeletal muscle.

\section{METHODS}

\section{Animal Treatment}

All animal procedures were in accordance with guidelines approved by the Bioethical Committee at the Facultad de Medicina, Universidad de Chile. Male 5-6 week-old BalbC mice $(20-30 \mathrm{~g})$ were intraperitoneally injected for 3 days with either the NOX2 inhibitor apocynin solution $(3 \mathrm{mg} / \mathrm{Kg})$ or vehicle as previously described (Khairallah et al., 2012). Apocynin (Sigma-Aldrich) solution was prepared in the dark at $12 \mathrm{mg} / \mathrm{mL}$ in absolute ethanol and then was diluted in sterile saline solution $(0.9 \% \mathrm{NaCl})$ in a dosage that has shown previously to inhibit NOX2 in vivo (Khairallah et al., 2012). In another set of experiments, mice were injected for 2 days with Pyrrolidinedithiocarbamate (PDTC), a NF- $\mathrm{kB}$ inhibitor $(50 \mathrm{mg} / \mathrm{Kg})$. PDTC (Sigma-Aldrich) solution was prepared in sterile saline solution $(0.9 \% \mathrm{NaCl})$ at $0.3 \mathrm{mg} / \mathrm{mL}$ for injections, as previously reported (Ji et al., 2004).

\section{Exercise Protocol}

Animals were divided into the following groups: Vehicletreated sedentary, Vehicle-treated plus exercise, Apocynintreated sedentary and Apocynin-treated plus exercise $(n=10$ mice for each group). The swimming groups of mice were acclimated to swimming for $10 \mathrm{~min}$ per day for 5 days without weight in the tail in order to minimize potential stress response. Afterwards, the mouse with the indicated treatment was gently placed in the water and performed $60 \mathrm{~min}$ of swimming exercise with a weight (5\% of their body weight) attached to the mousetail, this intensity has been proposed as moderate intensity in previous work and similar to other types of exercise (Contarteze et al., 2008). After the swimming time, mice were removed from the swimming pool, dried gently with paper towels and returned to their cages. A 1-liter beaker (11 cm diameter and $15 \mathrm{~cm}$ height) filled with water $\left(32 \pm 2^{\circ} \mathrm{C}\right)$ was used as a swimming pool to assess the exercise protocol. In another set of experiments mice were divided in two groups: Vehicle-treated and PDTC-treated plus exercise as described above ( $n=5$ mice for each group). For mRNA isolation, the animals were euthanized by cervical dislocation $2 \mathrm{~h}$ after the end of swimming exercise and flexor digitorum brevis (FDB) muscles were then stored at $-80^{\circ} \mathrm{C}$ until needed ( $n=5$ mice per group). Plasma, total proteins and 
muscle cryosection samples were obtained immediately after the end of the exercise protocol ( $n=5$ mice per group).

\section{Adult Skeletal Muscle Fiber Isolation}

FDB muscles were dissected from 5 to 6 week old mice as previously described (Altamirano et al., 2013). Briefly, muscle fibers were obtained by enzyme digestion of the whole muscle with collagenase type IV $(2.7 \mathrm{mg} / \mathrm{ml})$ (Worthington, Lakewood, $\mathrm{NJ}$ ) for $90 \mathrm{~min}$ at $37^{\circ} \mathrm{C}$ followed by mechanical dissociation with fire polished Pasteur pipettes. Isolated fibers were seeded in ECM Gel-coated (Sigma-Aldrich) dishes in DMEM supplemented with $10 \%$ horse serum. After $20 \mathrm{~h}$ of seeding, the fibers were used for experimentation.

\section{Electrical Stimulation (ES)}

Isolated skeletal muscle fibers were stimulated with a stimulation device that consists of six rows of platinum wires, intercalated $0.5 \mathrm{~cm}$ apart, with alternate polarity across a circular Teflon holder that fits in the dish. This was connected to a Grass S48 pulse generator, as previously described (Valladares et al., 2013). The protocol for ES used was one train of 250 square wave pulses of $0.5 \mathrm{~ms}$ duration at a frequency of $20 \mathrm{~Hz}(12.5 \mathrm{~s}$ total stimulation time). This protocol was previously shown to be effective in inducing both $\mathrm{Ca}^{2+}$ signaling and gene expression in adult skeletal muscle fibers (Jorquera et al., 2013). For NOX2 inhibition, the fibers were incubated either with $50 \mu \mathrm{M}$ apocynin (IC50 $10 \mu \mathrm{M}$ ) or $5 \mu \mathrm{M}$ of gp91-dstat (IC50 $1 \mu \mathrm{M}$ ) 30 min before ES, these concentrations are able to inhibit NOX2 in adult muscle fibers (Díaz-Vegas et al., 2015) and skeletal myotubes (Henríquez-Olguín et al., 2015).

\section{Western Blot}

FDB muscles were homogenized using an electric homogenizer (Fluko, Shanghai, China) in a lysis buffer containing in $\mathrm{mM}$ : 20Tris-HCl (pH 7.5), 1\% Triton X-100, 2 EDTA, $20 \mathrm{NaF}$, $1 \mathrm{Na}_{2} \mathrm{P}_{2} \mathrm{O}_{7}, 10 \%$ glycerol, $150 \mathrm{NaCl}, 10 \mathrm{Na}_{3} \mathrm{VO}_{4}, 1$ PMSF and protease inhibitors (Complete ${ }^{\mathrm{TM}}$, Roche Applied Science). Proteins were separated using SDS-PAGE and transferred to PVDF membranes. The following primary antibodies and their dilutions were used as follows: Total NF- $\mathrm{BB}$ total p65 subunit (1:1000; Cell Signaling); p-Ser536-p65 (1:1000; Cell Signaling); $\mathrm{p}^{\text {phox }}$ (1:5000; Sigma); p-p4 $7^{\text {phox }}$ (pSer359) (1:5000; Sigma); gp91 ${ }^{\text {phox }}$ (1:2000; BD Transduction); p-p38 (thr180/tyr182) (1:2000; Santa Cruz); p38 (1:2000; Santa Cruz); Phospho-ERK1/2(Thr202/Tyr204)(1:2000; Cell Signaling); ERK 1/2 (1:2000; Santa Cruz); $\alpha$-Tubulin (1:5000; Cell Signaling); antimouse IgG-HRP (1:20,000; Santa Cruz); anti-rabbit IgG-HRP (1:30,000; Thermo Scientific Pierce). The protein bands in the blots were visualized using a WESTAR Supernova detection kit (Cyanagen, Bologna, Italy) and ChemiDoc ${ }^{\mathrm{TM}}$ MP System (BioRad, USA). The intensity of the bands was determined with ImageJ densitometry analysis.

\section{Co-Immunoprecipitation Assay and Immunoblot (CoIP)}

Total FDB muscle proteins were lysed for $1 \mathrm{~h}$ lysis buffer on ice (in mM: 20Tris-HCl pH 7.4, 0.1\% Nonidet P-40, 5 EDTA pH 8, 10
EGTA pH 7.8, $140 \mathrm{NaCl}, 10 \%$ glycerol and protease inhibitors). Whole muscle lysates ( $100 \mu \mathrm{g}$ of protein) were spun at $15000 \mathrm{~g}$ for $20 \mathrm{~min}$ and the supernatant fraction was pre-cleared for $30 \mathrm{~min}$ with $10 \mu \mathrm{g}$ of A/G agarose. Pre-cleared lysates were separated by centrifugation and then were incubated along with the immunoprecipitating antibody for $4 \mathrm{~h}$. To pull down the immunecomplexes we incubated the samples with $50 \mu \mathrm{g} \mathrm{A} / \mathrm{G}$ agarose beads for $30 \mathrm{~min}$. Beads were spun down by centrifugation and washed 3 times with washing buffer in mM (25 HEPES pH $7.5,0.2 \%$ Nonidet P- $40,140 \mathrm{NaCl}, 0.1 \% \mathrm{BSA}, 10 \%$ glycerol and protease inhibitors). Proteins were resolved by SDS-PAGE in $7-10 \%$ gels, transferred to PVDF membranes and assayed with the corresponding antibodies.

\section{Proximity Ligation Assay (PLA)}

Cryosections $(10 \mu \mathrm{m}$ thick) from adult mice FDB muscle were fixed using freshly prepared para-formaldehyde (4\%) for $20 \mathrm{~min}$, washed 3 times with $0.1 \mathrm{M}$ PBS, pH 7.4, and blocked with PBS containing 5\% BSA for 1 h. P47 $7^{\text {phox }} / \mathrm{gp} 91^{\text {phox }}$ interaction was detected in situ using the Duolink ${ }^{\circledR}$ In Situ Red Starter Kit Mouse/Rabbit (Sigma-Aldrich) according to manufacturer instructions. Briefly, primary antibodies against $\mathrm{p} 47^{\text {phox }}$ and gp91 $1^{\text {phox }}$ were applied over night at $4^{\circ} \mathrm{C}$ in a humid chamber. Duolink plus and minus secondary antibodies against the primary antibodies were then incubated for $1 \mathrm{~h}$ at $37^{\circ} \mathrm{C}$. These secondary antibodies were provided as conjugates to oligonucleotides that were tied together in a closed circle by Duolink Ligation Solution, provided that the antibodies were in close proximity $(<40 \mathrm{~nm})$. Finally, polymerase was added, to amplify any existing closed circles, and detection was achieved with complementary fluorescently labeled oligonucleotides. To define fiber structure, after PLA assay an immunofluorescence against dystrophin was performed.

\section{mRNA Quantitation}

Total RNA was isolated from FDB muscles from both the apocynin- or vehicle-treated groups with TRIzol ${ }^{\circledR}$ reagent (Invitrogen) according to the manufacturer's protocol. Additionally, the same extraction protocol was used to obtain total RNA from isolated fibers that were electrical stimulated. CDNA was prepared by reverse transcription (RT) reaction of $1 \mu \mathrm{g}$ of total RNA using random primers. Real time PCR was performed as previously described (Altamirano et al., 2012) using the following primers: GAPDH: 5'-CTCATGACCACA GTCCATGC- $3^{\prime}$ and $5^{\prime}$-TTCAGCTCTGGGATGACCTT- $3^{\prime}$, IL-6: $5^{\prime}$-CCAATTTCCAATGCTCTCCT- $3^{\prime}$ and $5^{\prime}$-ACCACA GTGAGGAATGTCCA-3', CS: 5'-TGCTGGGGGTCTCCC TGTCC- $3^{\prime}$ and $5^{\prime}$-TGGGACCAGGCCCGAAGAGG-3', tfam: $5^{\prime}$-GCAAAGGATGATTCGGCTCAGGGAA- $3^{\prime}$ and $5^{\prime}$-CCG GATCGTTTCACACTTCGACGG-3'， MnSOD: $5^{\prime}$-TGGCTT GGCTTCAATAAGGA- ${ }^{\prime}$, and 5' -AAGGTAGTAAGCGTGCTC CCACAC-3', Gpx: 5'-GGGCTCCCTGCGGGGCAAGGT-3' and 5'-ATGTACTTGGGGTCGGTCATG-3'.

\section{IL-6 ELISA}

IL-6 protein levels in plasma were quantified using a mouse IL6 ELISA READY Kit (eBioscience) in each sample according to 

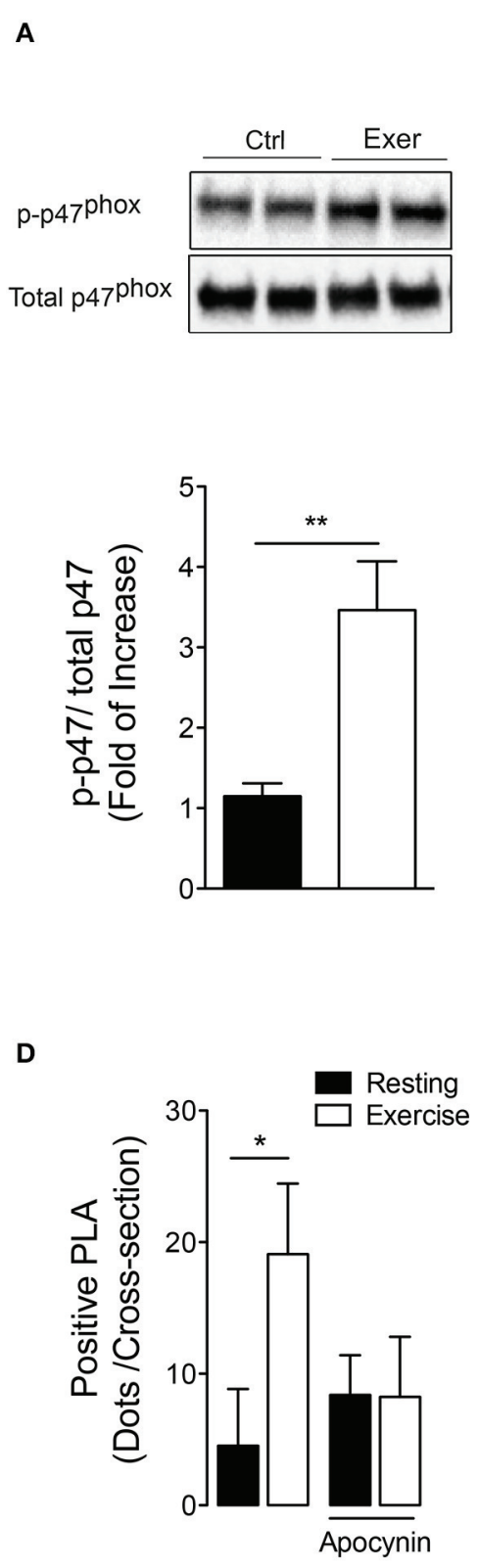

B

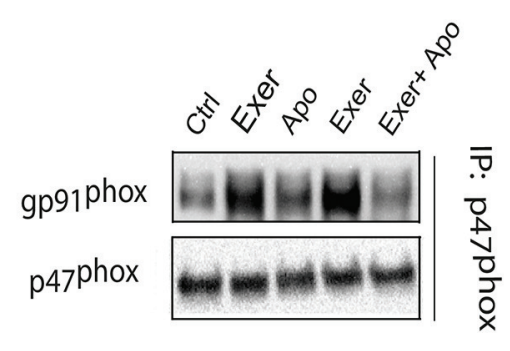

C

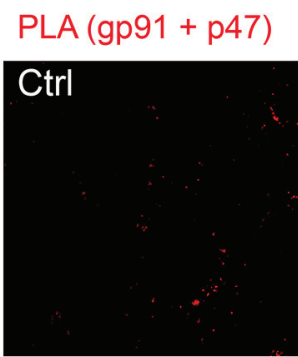

Dystrophin
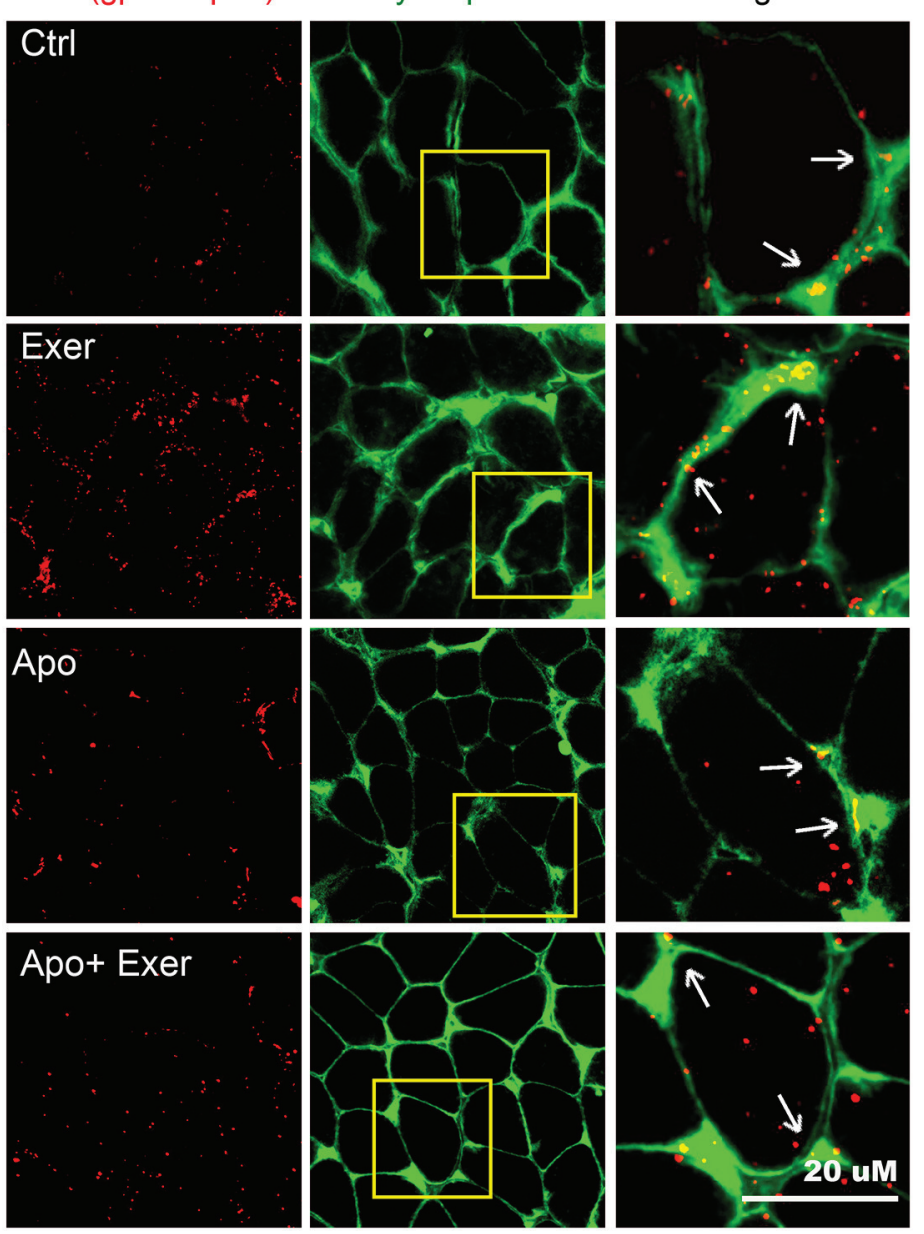

FIGURE 1 | Exercise-induced NOX2 activation was blocked by apocynin treatment. (A) Representative blot and quantitation of phospho-p47phox levels in FDB muscle under rest and exercise conditions. (B) gp91 phox/p47 phox interaction by co-immunoprecipitation in muscle lysates in control conditions (Ctrl), after exercise (Exer), control with apocynin (Apo, NOX2 blocker) and exercise without and with apocynin. (C) Representative in situ proximity ligation assay (PLA) probes and (D) quantification for gp $91^{\text {phox }}$ and p47 phox interaction as PLA dots after exercise in control and apocynin-treated mice. Anti-dystrophin antibody was used to define fiber perimeter. Arrows show colocalization of the PLA signal (red) with dystrophin (green). Data are expressed as mean \pm SD from five different determinations. ${ }^{*} p<0.05,{ }^{* *} p<0.01$; one-way ANOVA-Tukey and $t$-student were applied.

manufacturer's instructions. Mice were treated with the indicated inhibitor and then the plasma was collected immediately after $60 \mathrm{~min}$ of exercise through puncture. Absorbance was measured using a spectrophotometer (Synergy 2, BioTek, Winooski, USA).

\section{Statistical Analysis}

Data of $n$ experiments were expressed as mean \pm SD. The significance of difference among treatments was evaluated using a $t$-test for unpaired data or one-way ANOVA-followed by Tukey post hoc. A $P$-value $<0.05$ was considered statistically significant. 


\section{RESULTS}

\section{Exercise Activates NOX2 in Adult Skeletal Muscle}

Recent studies have shown that contractions are accompanied by a large cytosolic ROS production (Sakellariou et al., 2013; Pearson et al., 2014), and suggest a major role for non-mitochondrial sources (Sakellariou et al., 2014). To address whether an acute endurance exercise can activate NOX2 in skeletal muscle, mice performed $60 \mathrm{~min}$ of non-exhaustive swimming exercise. We studied $\mathrm{p} 47^{\text {phox }}$ phosphorylation immediately following exercise. Swimming exercise induced significant increases of phospho-p $47^{\text {phox }}$ levels compared with unexercised mice $(\sim 3$ fold, $p<0.01$; Figure 1A).

To address whether apocynin is blocking the NOX2 assembly, we determined interactions between cytosolic $\left(\mathrm{p} 47^{\mathrm{phox}}\right)$ and membrane-bound subunit (gp91 ${ }^{\text {phox }}$ ) in FDB muscle using two approaches. First, we showed that swimming exercise increases the protein-protein interaction between these subunits measured by co-immunoprecipitation. More importantly, the interaction between $\mathrm{p} 47^{\mathrm{phox}}$ and $\mathrm{gp} 91^{\text {phox }}$ was disrupted by apocynin, a NOX2 blocker, treatment (Figure 1B). Second, we used the proximity ligation assay (PLA) to further demonstrate interactions between NOX2 subunits. This technique shows proximity as fluorescence dots when the two proteins assessed are nearer than $40 \mathrm{~nm}$. Swimming exercise increased around 4-fold the number of positive PLA dots ( $\mathrm{p} 47^{\text {phox }}-\mathrm{gp} 91^{\text {phox }}$ proximity) in FDB muscle $(p<0.05$; Figures 1C,D). Interestingly, exercise-induced $\mathrm{p} 47^{\text {phox }}-\mathrm{gp} 91^{\text {phox }}$ proximity was prevented by apocynin treatment, without any effect in the basal levels (Figures 1C,D).

\section{NOX2 Activation is Necessary for ERK1/2, p38, and NF-kB Signaling Induced by Exercise}

General ROS scavengers reduce the mitogen-activated protein kinase (MAPK) phosphorylation during exercise (Paulsen et al., 2014a). In order to determine the role of NOX2 in exerciseinduced MAPK activation, we studied the changes of these pathways by Western blot using phospho-specific antibodies. Swimming exercise significantly increased ERK 1/2 (Thr202, Tyr204) and p38 phosphorylation by $\sim 2$-fold $(p<0.01$ ), compared with unexercised mice in FDB (Figures 2A,C) and Gastrocnemius (data not shown) muscles. Interestingly, apocynin treatment totally blocked these activations in FDB muscle from exercised mice (Figures $2 \mathrm{~B}, \mathrm{C}$ ).

$\mathrm{NF}-\kappa \mathrm{B}$ is a classic redox sensitive transcription factor that controls the expression of antioxidant enzymes and the myokine IL-6 (Ji et al., 2004). To determine if exercise-induced NOX2 activation participates in NF- $\kappa \mathrm{B}$ signaling pathway activation, we measured p-p65 levels after exercise in vehicle- and apocynintreated mice. Swimming increased $\mathrm{p} 65$ phosphorylation (Ser536) by 3 -fold in FDB muscle compared with control mice (Figures 2D,E, $p<0.01$ ). In addition, apocynin treatment impaired NF- $\kappa \mathrm{B}$ activation in exercised muscle (Figures 2D,E, $p<0.05)$.

\section{Exercise-Induced Muscle and Plasma IL-6 Increments Were Blunted by NOX2 Inhibition}

IL-6 is a key myokine involved in acute and chronic response to exercise in skeletal muscle (Pedersen and Febbraio, 2012). In order to study the participation of NOX2-activation on IL6 expression, we measured IL- 6 mRNA content in swimming exercised FDB muscle. Exercise induced a robust increment in IL- 6 mRNA by $\sim 7.5$-fold compared to control mice ( $p<0.001$ ), which was blocked by apocynin (Figure 3A). In order to determine whether the apocynin effect was due to NOX2 blockage, we corroborated these results using the peptide gp91-dstat, a specific NOX2 inhibitor, on isolated FDB fibers in response to electrical stimulus (ES, an in vitro exercise protocol) (Figure 3B). In isolated FDB fibers, IL-6 mRNA levels were upregulated by ES and this increase was blocked by NOX2 inhibitors apocynin $(50 \mu \mathrm{M})$ and gp91-dstat $(5 \mu \mathrm{M})$. Additionally, we evaluated the participation of NF- $\mathrm{B}$ in exercise induced IL-6 expression. When exercised mice were treated with PDTC (a NF- $\kappa$ B inhibitor) the increase in IL-6 expression was totally blunted (Figure 3A). Similar result was obtained in isolated fibers incubated with the NF- $\kappa$ B inhibitor SN50 $(10 \mu \mathrm{M})$ and electrically stimulated (Figure 3B).

We also evaluated the plasma IL-6 concentration immediately after exercise in vehicle- and apocynin-treated mice. Figure 3C shows that plasma IL- 6 was increased $\sim 7$-fold in exercisedmice compared to control (1.9 vs. $14.7 \mathrm{pg} / \mathrm{ml}, p<0.001)$. The apocynin-treated group showed $\sim 40 \%$ less plasma IL-6 increase compared to vehicle-treated in exercising conditions (6.4 vs. 14.7 $\mathrm{pg} / \mathrm{ml}, p<0.01)$.

\section{NOX2-Activation is Required for Exercise-Induced Antioxidant and Mitochondrial mRNA Markers}

We studied the changes in antioxidant and metabolic mRNA markers in FDB muscle lysates $2 \mathrm{~h}$ after $60 \mathrm{~min}$ of swimming exercise using real time RT-qPCR. Swimming exercise significantly increased the mRNA levels of manganese superoxide dismutase (MnSOD) (Figure 4A), and Glutathione peroxidase (GPx) (Figure 4B) in 2.5- and 4.5-fold, respectively $(p<0.05)$. Interestingly, these effects were partially ablated by apocynin treatment (Figures 4A,B).

Tfam is necessary and sufficient to induce mitochondrial biogenesis (Ikeuchi et al., 2005). We addressed whether NOX2 inhibition can impair mitochondrial biogenesis signaling by studying the changes in the mRNA levels of mitochondrial transcription factor A (tfam) and citrate synthase (CS). Our results show that the levels of both tfam and CS mRNA were increased about 4 folds under exercising conditions $(p<0.05$ and $p<0.01$ respectively, Figures 4C,D). Apocynin treatment prevented the exercise-induced mRNA increment, suggesting the participation of NOX2 in exercise-induced mitochondrial gene activation in skeletal muscle.

We also corroborated these results using the peptide gp91dstat on isolated FDB fibers in response to electrical stimulation. As shown in Figure 5, ES significantly increased mRNA levels of 


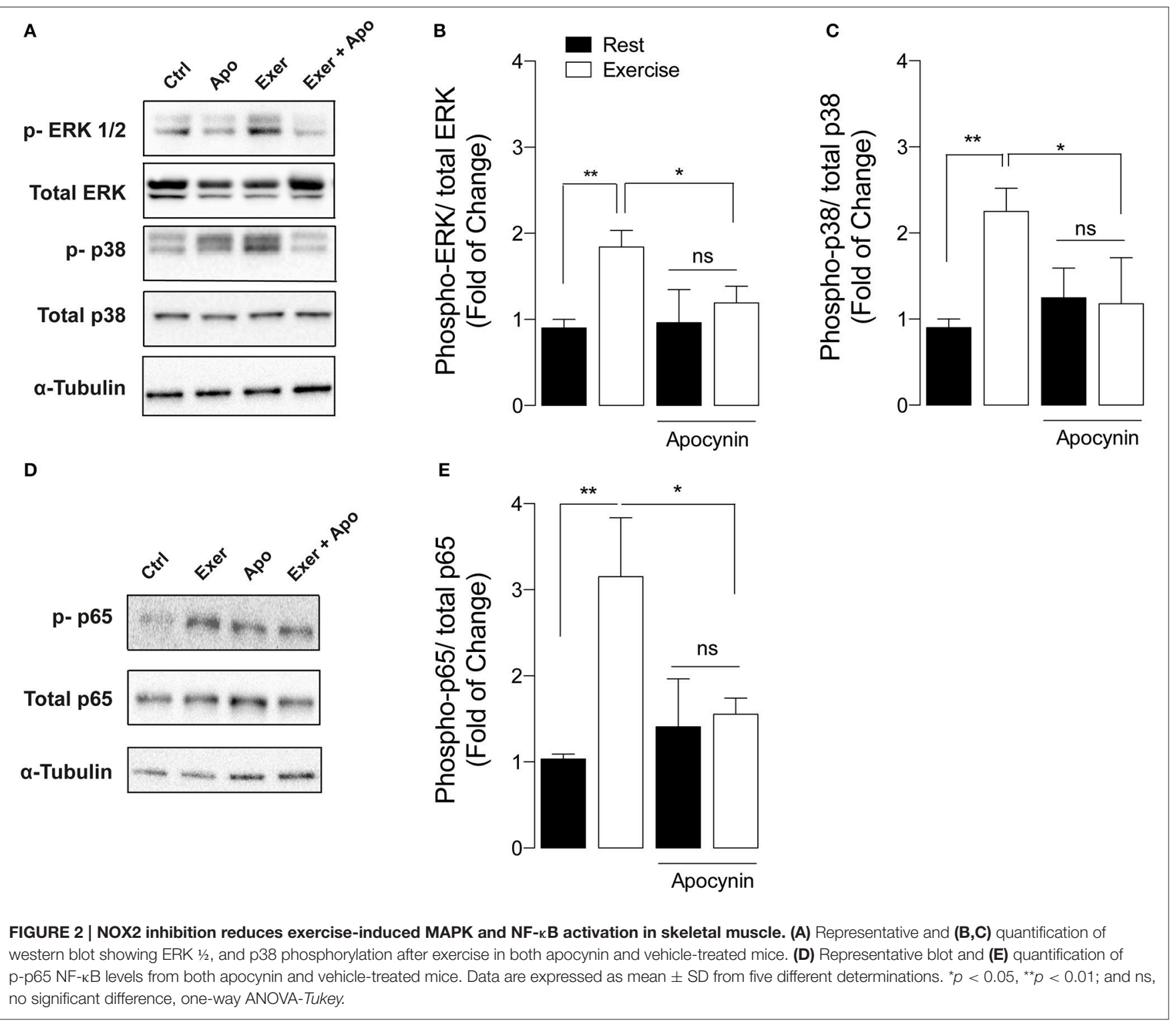

MnSOD, GPx, CS and tfam. Both apocynin (50 $\mu \mathrm{M})$ and gp91dstat $(5 \mu \mathrm{M})$ completely blunted the increase in mRNA levels induced by ES for all the studied mRNAs.

\section{DISCUSSION}

The present study aims to determine the participation of NOX2 in molecular events induced by a single bout of exercise in skeletal muscle. The main finding was that endurance exercise activates NOX2, and subsequently modulates ROS-sensitive pathways to promote gene transcription. To the best of our knowledge, this is the first study to show in vivo NOX2 activation during exercise and its participation in exercise-induced redox signaling in skeletal muscle.

ROS act as signaling molecules that participate in traininginduced skeletal muscle adaptation (Gomez-Cabrera et al.,
2008; Ristow et al., 2009; Strobel et al., 2011). There is increasing evidence that localized ROS signaling at specific subcellular compartment is essential for redox sensitive pathways modulation (Ushio-Fukai, 2006). Thus, the ROS source that contributes to exercise-induced molecular signaling could be a key piece of skeletal muscle physiology (Jackson et al., 2016 for review). It has been previously reported that xanthine oxidase-derived ROS is a dispensable source for skeletal muscle adaptation following 6-weeks of endurance training (Wadley et al., 2013). More recently, several groups have shown that NOX2 is the major ROS source during muscle contraction in both cultured myotubes and isolated fibers (Espinosa et al., 2013; Sakellariou et al., 2013; Pearson et al., 2014; Díaz-Vegas et al., 2015; Henríquez-Olguín et al., 2015). However, the experimental evidence showing that exercise is sufficient to activate NOX2 was still lacking. In the present study, we showed that an 

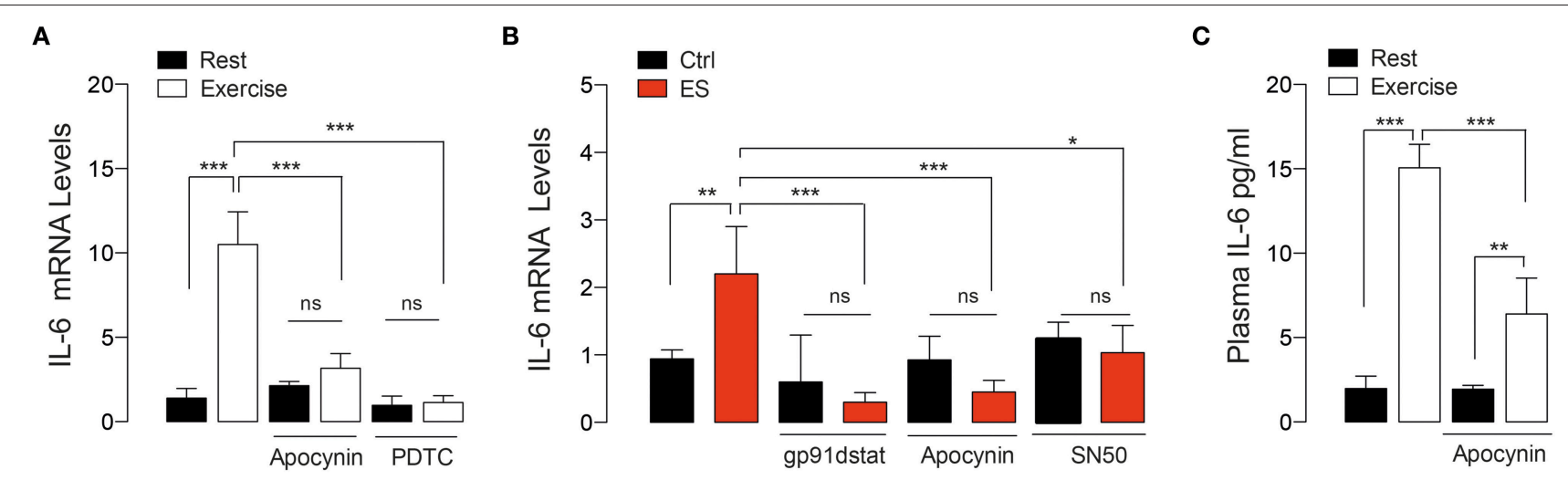

FIGURE 3 | NOX2-dependent ROS production is involved in IL-6 gene expression induced by both in vivo and in vitro exercise. (A) Levels of muscle IL-6 mRNA after exercise in mice treated with vehicle, apocynin and PDTC (NF-kB inhibitor). (B) Levels of IL-6 mRNA in isolated skeletal muscle fibers that were pre-incubated with either apocynin or gp91-dstat (NOX2 blockers) or SN50 (NF-кB inhibitor) before electrical stimulation (ES). (C) Plasma IL-6 levels obtained immediately after exercise in both apocynin- or saline-treated mice. Data are expressed as mean $\pm \mathrm{SD}$ from five different determinations. ${ }^{\star} p<0.05$, ${ }^{* *} p<0.01$, ${ }^{* * *} p<0.001 ;$ ns, no significant difference, one-way ANOVA-Tukey.

acute endurance exercise was a powerful stimulus for NOX2 activation in FDB muscle. The fact that exercise induces NOX2 activation has meaningful implications for understanding the role of localized redox homeostasis in striated muscle (Sánchez et al., 2008; Hidalgo and Donoso, 2011; Wang et al., 2015). We propose that NOX2 plays a critical role in regulated ROSdependent signaling in skeletal muscle induced by endurance exercise. Even though the evidence support that ROS generated by NOX2 participate in signal transduction, the mechanisms by which contraction activates NADPH oxidase and regulates ROS generation are poorly understood. Recently, our laboratory has proposed that ATP release from skeletal muscles can act as NOX2 activator through activation of $\mathrm{P} 2 \mathrm{Y}_{1}$ receptors and a PKC-dependent pathway (Díaz-Vegas et al., 2015). Future works should determine the mechanisms involved in in vivo exerciseinduced NOX2 activation.

Apocynin has been widely used as a NOX2 inhibitor (Sánchez et al., 2008; Yokota et al., 2009; Khairallah et al., 2012; Espinosa et al., 2013; Díaz-Vegas et al., 2015; Henríquez-Olguín et al., 2015), however its use is controversial. Some in vitro studies have shown that apocynin can induce ROS generation or has antioxidants properties (Vejrazka et al., 2005). However, the efficacy of apocynin during in vivo conditions has largely been reported (Khairallah et al., 2012; Espinosa et al., 2013; YamacitaBorin et al., 2015; Cheng et al., 2016; Zhu et al., 2016). In the present study, we confirmed that apocynin is able to disrupt the assembly of the NOX2 complex during in vivo exercise. The results obtained in vitro using both apocynin and gp91dstat peptide confirm that NOX2 inhibition alter intracellular signaling induced by exercise and electrical stimulation. Even though the evidence support that apocynin is blocking NOX2 assembly and ROS production, we cannot exclude other side effects of our treatment. Future studies should explore gene silencing and genetic tools for NOX2 inhibition.

It is well described that exercise activates ERK and p38 MAPK pathways in animal (Goodyear et al., 1996) and human (Osman et al., 2000) skeletal muscle in a redox sensitive manner (Paulsen et al., 2014a). During contraction, activation of the p38 MAPK in adult skeletal muscle results in enhanced mitochondrial biogenesis (Akimoto et al., 2005). Different research groups have shown that ROS scavengers attenuate p38 and ERK activation induced by exercise in muscle tissue (Michailidis et al., 2013). In human skeletal muscle precursor cells, NOX2 has proven to be critical for both myoblast proliferation and differentiation through ERK 1/2 pathway (Mofarrahi et al., 2008). Interestingly, the present study showed that NOX2 inhibition impairs MAPK activation after a single bout of endurance exercise in skeletal muscle, suggesting that ROS-derived from NOX2 are necessary for this pathways activation.

$\mathrm{NF}-\kappa \mathrm{B}$ is a well-described redox sensitive transcription factor (Michailidis et al., 2013; Wadley et al., 2013), which is activated by exercise in skeletal muscle (Aoi et al., 2004; Ji et al., 2004). It has been proposed that exercise-induced NF- $\mathrm{B}$ activation participates in acute and chronic responses to exercise (Feng et al., 2013). For example, PDTC administration reduces exerciseinduced antioxidant gene expression (Ji et al., 2004) and impairs mitochondrial biogenesis after long-term training (Feng et al., 2013), suggesting that NF- $\kappa B$ is essential for adequate response to exercise/training. It is well described that NOX2 induces NF- $\kappa$ B activation in several tissues (Brar et al., 2002; Yao et al., 2007; Li et al., 2009) including skeletal muscle cells (Mofarrahi et al., 2008). We have previously shown that NOX2 is required for transcriptional activation of NF- $\mathrm{B}$ induced by electrical stimulation in skeletal myotubes (Henríquez-Olguín et al., 2015). Here, our results demonstrate that exercise-induced phospho-p65 NF- $\kappa$ B increment was blunted in apocynin-treated mice. Together, these antecedents suggest that transcriptional activation of NF- $\kappa \mathrm{B}$ could be modulated by NOX2-dependent ROS production during exercise in skeletal muscle.

Myokines play a critical role modulating whole body metabolism during endurance and resistance exercise (Steensberg et al., 2000; Glund et al., 2007). A close relationship 


\section{A}

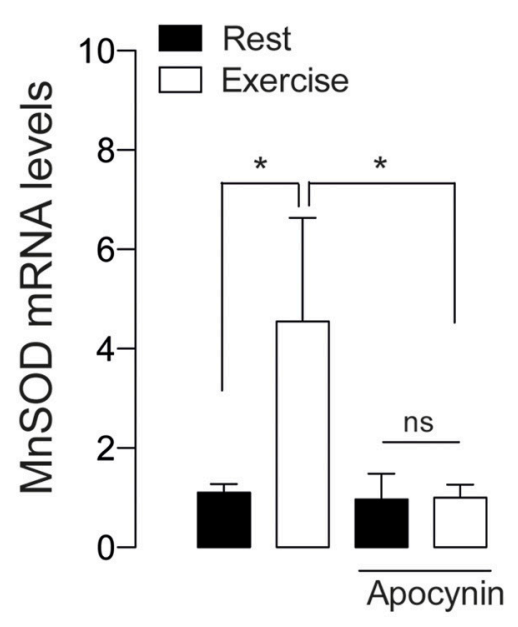

C

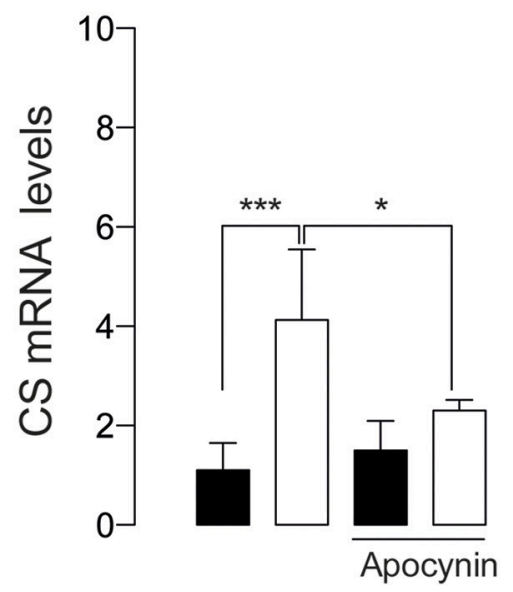

B

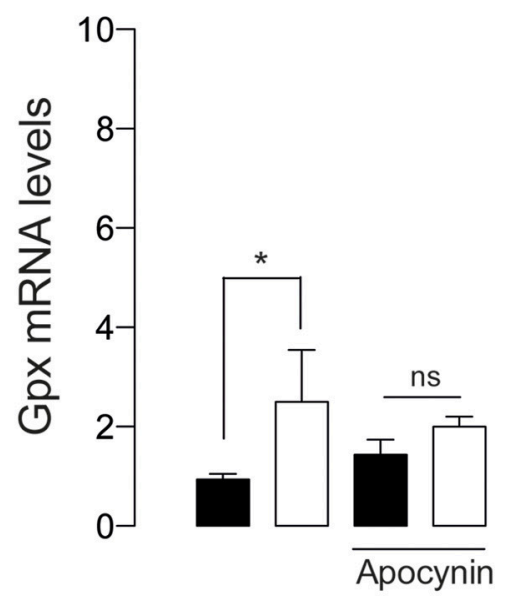

D

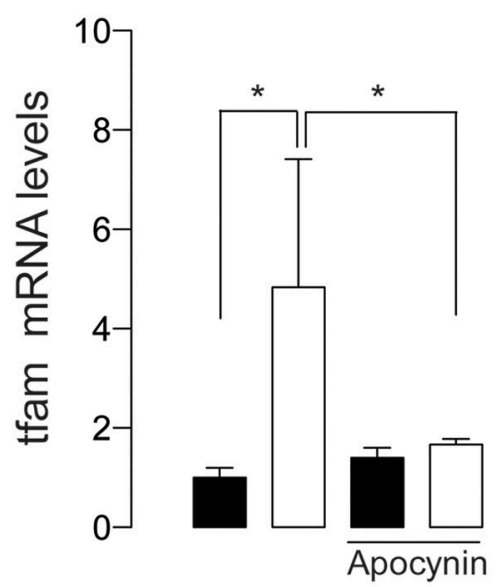

FIGURE 4 | NOX2 activation is necessary for exercise-induced antioxidant and mitochondrial gene expression. (A) Levels of mRNA for manganese superoxide dismutase (MnSOD), (B) Glutathione peroxidase (Gpx), (C) Citrate synthase (CS), and (D) mitochondrial transcription factor A (tfam) mRNAs were assessed by real time PCR in FDB muscle after swimming exercise. Data are expressed as mean \pm SD from five different determinations. ${ }^{*} p<0.05,{ }^{* * *} p<0.001 ;$ ns, no significant difference, one-way ANOVA-Tukey.

between ROS production and myokine production during exercise has been suggested (for review see Scheele et al., 2009). For example, IL-6 is a well-established myokine released by the skeletal muscle during exercise, whose levels are decreased by general antioxidants supplementation (Fischer et al., 2004; Yfanti et al., 2012). Moreover, in adipose tissue, NOX2 deficient mice have reduced IL-6 expression (Costford et al., 2014). Interestingly, in the present work, swimming and running (data not shown) increased both plasma and muscle mRNA of IL-6 in vehicle-treated mice; these effects were decreased by apocynin treatment. Additionally, both apocynin and gp91dstat decreased electrical stimuli-induced IL-6 gene expression in single fibers. On the other hand, unpublished observations from our lab using a mitochondrial-target antioxidant EUK-134, was not able to disrupt electrical stimulation-induced IL-6 expression. Together, these data strongly suggest NOX2-derived ROS production is critical for IL-6 expression and the subsequent release from skeletal muscles during exercise.

IL-6 gene has binding sites for NF- $\mathrm{KB}$ in its promoter regions (Libermann and Baltimore, 1990) and also we described that IL-6 expression induced by electrical stimulation is regulated by NF$\kappa \mathrm{B}$ activity in skeletal myotubes (Juretić et al., 2006; HenríquezOlguín et al., 2015). Here, the results show that IL-6 expression following exercise or electrical stimulation is lowered by both PDTC and SN50, known NF- $\mathrm{BB}$ inhibitors. Together, these data demonstrated that NOX2 plays a critical role in NF- $\mathrm{kB}$ activation and the subsequent modulation of IL-6 gene expression in skeletal muscle under exercising conditions.

It is well known that antioxidant gene expression is increased in response to exercise training in mice (Hollander et al., 2001) 


\section{A}

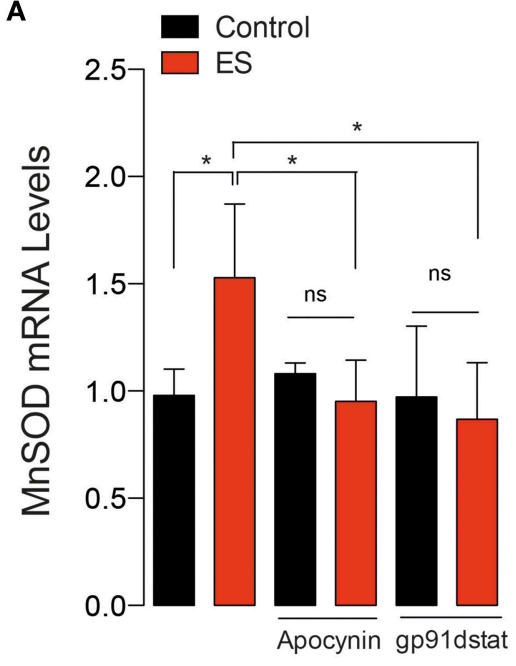

C

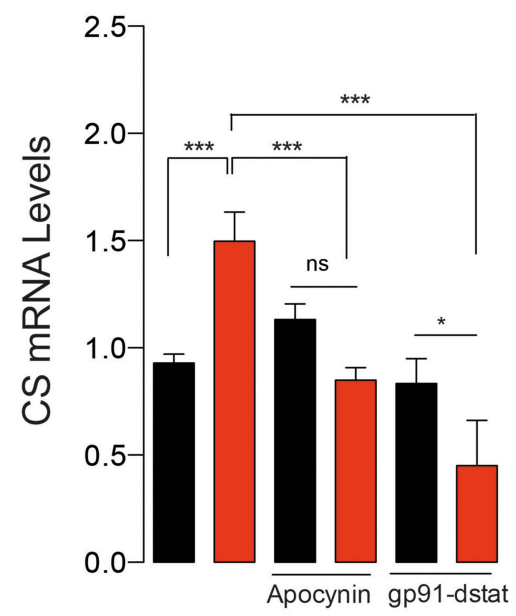

B

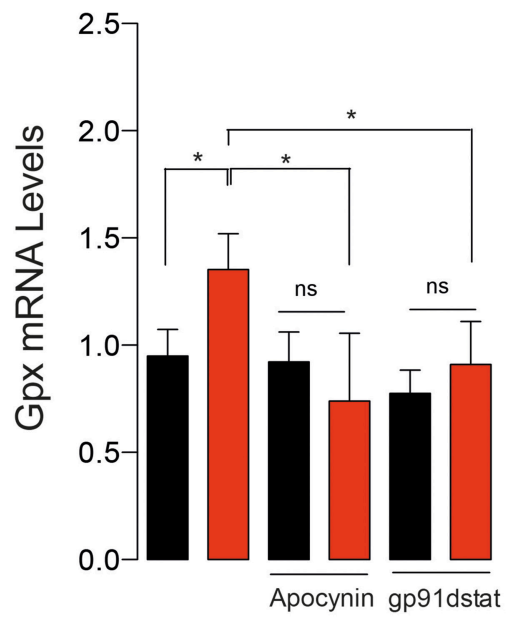

D

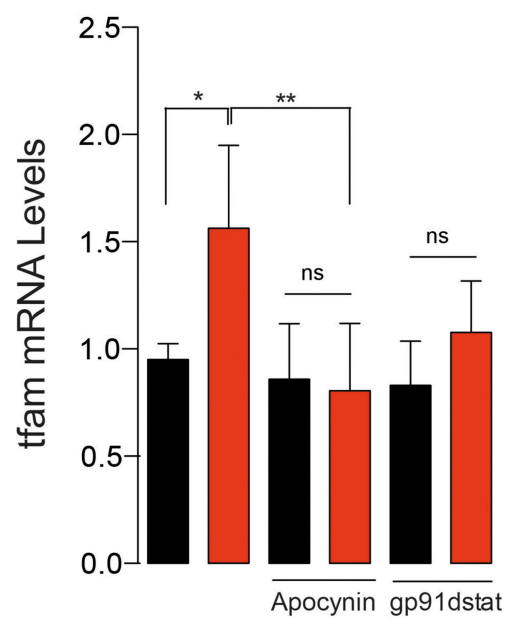

FIGURE 5 | In vitro electrical stimulation-induced gene expression in a NOX2-dependent manner. (A) Levels of mRNA for manganese superoxide dismutase (MnSOD), (B) Glutathione peroxidase (Gpx), (C) Citrate synthase (CS) and (D) Mitochondrial transcription factor A (tfam). Gene transcription was assessed by real time PCR in isolated skeletal muscle fibers in the presence and absence of the NOX2 inhibitor gp91-dstat before electrical stimulation (ES). Data are expressed as mean \pm SD from five different determinations. ${ }^{*} p<0.05,{ }^{* *} p<0.01,{ }^{* *} p<0.001$; ns, no significant difference, one-way ANOVA-Tukey.

and humans (Ristow et al., 2009). Our results show that skeletal muscle responds to a single bout of exercise or electrical stimulus with an increase in the transcription of both MnSOD and GPx genes. Moreover, NOX2 inhibition, by apocynin or gp91dstat, prevents the exercise-induced mRNA upregulation. Our findings are in agreement with previous studies showing that general ROS scavengers decrease training/exercise-induction of both MnSOD and GPx gene expression in animal (GomezCabrera et al., 2008) and human (Ristow et al., 2009; Petersen et al., 2012) skeletal muscle. Interestingly, MnSOD and GPx present NF- $\mathrm{B}$-binding sites in their promoter regions (Allen and Tresini, 2000), suggesting a NOX2/NF- $\mathrm{B}$ pathway that may be involved in the regulation of gene activation induced by exercise.

Mitochondrial biogenesis is a key adaptation to increase endurance capacity (Hood, 2009). Tfam is a transcription factor necessary and sufficient for mitochondria biogenesis through the upregulation expression of mitochondrial proteins and other factors involved in mtDNA transcription and replication (Ikeuchi et al., 2005). The present study provides evidence that NOX2 inhibition blunts the Tfam mRNA upregulation induced by both exercise and electrical stimulation. This result is in line with previous studies showing that ROS scavengers as vitamin $\mathrm{C}$ disrupt training-induced tfam mRNA increment in rat skeletal muscle (Gomez-Cabrera et al., 2008). Citrate synthase (CS) has been extensively used as a metabolic marker for assessing mitochondrial oxidative capacity after endurance and resistance training (Larsen et al., 2012). NOX2 inhibition by both gp91dstat and apocynin reduces the CS mRNA after exercise or ES. These results may explain previous reports where dietary antioxidants reduced mitochondrial content in response to exercise (Gomez-Cabrera et al., 2008; Ristow et al., 2009; Strobel et al., 2011; Paulsen 
et al., 2014a). Our data support the hypothesis that exerciseinduced mitochondrial gene expression is a redox sensitive process (Sano and Fukuda, 2008) and it is affected by specific inhibitors of NOX2-dependent ROS production. Adaptations to exercise training is produced from the cumulative effect of transient increases in mRNA transcripts that encode for various proteins after each successive exercise bout (Perry et al., 2010). Here, we show that an acute exercise is a powerful stimulus to activate NOX2 and promote adaptive molecular response to exercise in skeletal muscle. However, we cannot directly extrapolate our results to long-term training adaptation.

In summary, we provide evidence indicating that NOX2 is activated by endurance exercise promoting downstream pathways and gene activation in skeletal muscle. These findings provide insights into our understanding ROS homeostasis and ROS signaling induced by exercise in skeletal muscle. The role of NOXs in metabolic adaptation and long-term training effects remains to be determined.

\section{REFERENCES}

Akimoto, T., Pohnert, S. C., Li, P., Zhang, M., Gumbs, C., Rosenberg, P. B., et al. (2005). Exercise stimulates Pgc-1alpha transcription in skeletal muscle through activation of the p38 MAPK pathway. J. Biol. Chem. 280, 19587-19593. doi: 10.1074/jbc.M408862200

Allen, R. G., and Tresini, M. (2000). Oxidative stress and gene regulation. Free Radic. Biol. Med. 28, 463-99. doi: 10.1016/S0891-5849(99)00242-7

Altamirano, F., López, J. R., Henríquez, C., Molinski, T., Allen, P. D., and Jaimovich, E. (2012). Increased resting intracellular calcium modulates NF- $\kappa$ B-dependent inducible nitric-oxide synthase gene expression in dystrophic mdx skeletal myotubes. J. Biol. Chem. 287, 20876-20887. doi: 10.1074/jbc.M112.344929

Altamirano, F., Valladares, D., Henriquez-Olguin, C., Casas, M., Lopez, J. R., Allen, P. D., et al. (2013). Nifedipine treatment reduces resting calcium concentration, oxidative and apoptotic gene expression, and improves muscle function in dystrophic mdx mice. PLoS ONE 8:e81222. doi: 10.1371/journal.pone.00 81222

Aoi, W., Naito, Y., Takanami, Y., Kawai, Y., Sakuma, K., Ichikawa, H., et al. (2004). Oxidative stress and delayed-onset muscle damage after exercise. Free Radic. Biol. Med. 37, 480-487. doi: 10.1016/j.freeradbiomed.2004. 05.008

Brar, S. S., Kennedy, T. P., Sturrock, A. B., Huecksteadt, T. P., Quinn, M. T., Murphy, T. M., et al. (2002). NADPH oxidase promotes NF-kappaB activation and proliferation in human airway smooth muscle. Am. J. Physiol. Lung Cell. Mol. Physiol. 282, L782-L795. doi: 10.1152/ajplung.00206.2001

Cheng, X., Zheng, X., Song, Y., Qu, L., Tang, J., Meng, L., et al. (2016). Apocynin attenuates renal fibrosis via inhibition of NOXs-ROSERK-myofibroblast accumulation in UUO rats. Free Radic. Res. doi: 10.1080/10715762.2016.1181757. [Epub ahead of print].

Contarteze, R. V., Manchado Fde, B., Gobatto, C. A., and De Mello, M. A. (2008). Stress biomarkers in rats submitted to swimming and treadmill running exercises. Comp. Biochem. Physiol. A. Mol. Integr. Physiol. 151, 415-422. doi: 10.1016/j.cbpa.2007.03.005

Costford, S. R., Castro-Alves, J., Chan, K. L., Bailey, L. J., Woo, M., Belsham, D. D., et al. (2014). Mice lacking NOX2 are hyperphagic and store fat preferentially in the liver. Am. J. Physiol. Endocrinol. Metab. 306, E1341-E1353. doi: 10.1152/ajpendo.00089.2014

Díaz-Vegas, A., Campos, C. A., Contreras-Ferrat, A., Casas, M., Buvinic, S., Jaimovich, E., et al. (2015). ROS Production via P2Y1-PKC-NOX2 Is Triggered by Extracellular ATP after Electrical Stimulation of Skeletal Muscle Cells. PLoS ONE 10:e0129882. doi: 10.1371/journal.pone.0129882

\section{AUTHOR CONTRIBUTIONS}

The study concept was developed by $\mathrm{CH}, \mathrm{AD}$, and DV. All authors were involved in executing the experiments, data collection and conducting measurements. $\mathrm{CH}, \mathrm{EJ}$, and DV, performed data analysis and were responsible for writing the manuscript. All authors contributed to the intellectual content and editing of the manuscript, and approved the final version.

\section{FUNDING}

FONDECYT 1151293 (EJ), FONDECYT 3140491 (DV) and PhD Fellowships (CH, ADV, YUM and MAC) funded this work by Comisión Nacional de Ciencia y Tecnología (CONICYT).

\section{ACKNOWLEDGMENTS}

The authors wish to thank Monica Silva for her technical assistance in skeletal muscle fibers preparation.

Espinosa, A., Campos, C., Díaz-Vegas, A., Galgani, J. E., Juretic, N., OsorioFuentealba, C., et al. (2013). Insulin-dependent $\mathrm{H}_{2} \mathrm{O}_{2}$ production is higher in muscle fibers of mice fed with a high-fat diet. Int. J. Mol. Sci. 14, 15740-15754. doi: 10.3390/ijms140815740

Espinosa, A., Henríquez-Olguín, C., and Jaimovich, E. (2016). Reactive oxygen species and calcium signals in skeletal muscle: a crosstalk involved in both normal signaling and disease. Cell Calcium. doi: 10.1016/j.ceca.2016.02.010. [Epub ahead of print].

Feng, H., Kang, C., Dickman, J. R., Koenig, R., Awoyinka, I., Zhang, Y., et al. (2013). Training-induced mitochondrial adaptation: role of peroxisome proliferatoractivated receptor $\gamma$ coactivator- $1 \alpha$, nuclear factor- $\kappa \mathrm{B}$ and $\beta$-blockade. Exp. Physiol. 98, 784-795. doi: 10.1113/expphysiol.2012.069286

Fischer, C. P., Hiscock, N. J., Penkowa, M., Basu, S., Vessby, B., Kallner, A., et al. (2004). Supplementation with vitamins C and E inhibits the release of interleukin-6 from contracting human skeletal muscle. J. Physiol. 558, 633-645. doi: 10.1113/jphysiol.2004.066779

Glund, S., Deshmukh, A., Long, Y. C., Moller, T., Koistinen, H. A., Caidahl, K., et al. (2007). Interleukin-6 directly increases glucose metabolism in resting human skeletal muscle. Diabetes 56, 1630-1637. doi: 10.2337/db06-1733

Gomez-Cabrera, M.-C., Borrás, C., Pallardó, F. V., Sastre, J., Ji, L. L., and Viña, J. (2005). Decreasing xanthine oxidase-mediated oxidative stress prevents useful cellular adaptations to exercise in rats. J. Physiol. 567, 113-120. doi: 10.1113/jphysiol.2004.080564

Gomez-Cabrera, M. C., Domenech, E., Romagnoli, M., Arduini, A., Borras, C., Pallardo, F. V., et al. (2008). Oral administration of vitamin C decreases muscle mitochondrial biogenesis and hampers training-induced adaptations in endurance performance. Am. J. Clin. Nutr. 87, 142-149.

Goodyear, L. J., Chang, P. Y., Sherwood, D. J., Dufresne, S. D., and Moller, D. E. (1996). Effects of exercise and insulin on mitogen-activated protein kinase signaling pathways in rat skeletal muscle. Am. J. Physiol. 271, E403-E408.

Henríquez-Olguín, C., Altamirano, F., Valladares, D., López, J. R., Allen, P. D., and Jaimovich, E. (2015). Altered ROS production, NF-кB activation and interleukin- 6 gene expression induced by electrical stimulation in dystrophic mdx skeletal muscle cells. Biochim. Biophys. Acta 1852, 1410-1419. doi: 10.1016/j.bbadis.2015.03.012

Hidalgo, C., and Donoso, P. (2011). Cell signaling. Getting to the heart of mechanotransduction. Science 333, 1388-1390. doi: 10.1126/science.12 12183

Hidalgo, C., Sánchez, G., Barrientos, G., and Aracena-Parks, P. (2006). A transverse tubule NADPH oxidase activity stimulates calcium release from isolated triads via ryanodine receptor type $1 \mathrm{~S}$-glutathionylation. J. Biol. Chem. 281, 26473-26482. doi: 10.1074/jbc.M600451200 
Hollander, J., Fiebig, R., Gore, M., Ookawara, T., Ohno, H., and Ji, L. L. (2001). Superoxide dismutase gene expression is activated by a single bout of exercise in rat skeletal muscle. Pflugers Arch. 442, 426-434. doi: 10.1007/s0042401 00539

Hood, D. A. (2009). Mechanisms of exercise-induced mitochondrial biogenesis in skeletal muscle. Appl. Physiol. Nutr. Metab. 34, 465-472. doi: 10.1139/H09-045

Hood, D. A., Tryon, L. D., Vainshtein, A., Memme, J., Chen, C., Pauly, M., et al. (2015). Exercise and the regulation of mitochondrial turnover. Prog. Mol. Biol. Transl. Sci. 135, 99-127. doi: 10.1016/bs.pmbts.2015.07.007

Ikeuchi, M., Matsusaka, H., Kang, D., Matsushima, S., Ide, T., Kubota, T., et al. (2005). Overexpression of mitochondrial transcription factor a ameliorates mitochondrial deficiencies and cardiac failure after myocardial infarction. Circulation 112, 683-690. doi: 10.1161/CIRCULATIONAHA.104.524835

Jackson, M. J. (2011). Control of reactive oxygen species production in contracting skeletal muscle. Antioxid. Redox Signal. 15, 2477-2486. doi: 10.1089/ars.2011.3976

Jackson, M. J. (2016). Recent advances and long-standing problems in detecting oxidative damage and reactive oxygen species in skeletal muscle. J. Physiol. doi: 10.1113/jp270657. [Epub ahead of print].

Jackson, M. J., Vasilaki, A., and McArdle, A. (2016). Cellular mechanisms underlying oxidative stress in human exercise. Free Radic. Biol. Med. doi: 10.1016/j.freeradbiomed.2016.02.023. [Epub ahead of print].

Ji, L. L., Gomez-Cabrera, M.-C., Steinhafel, N., and Vina, J. (2004). Acute exercise activates nuclear factor (NF)-kappaB signaling pathway in rat skeletal muscle. FASEB J. 18, 1499-1506. doi: 10.1096/fj.04-1846com

Jorquera, G., Altamirano, F., Contreras-Ferrat, A., Almarza, G., Buvinic, S., Jacquemond, V., et al. (2013). Cav1.1 controls frequency-dependent events regulating adult skeletal muscle plasticity. J. Cell Sci. 126, 1189-1198. doi: $10.1242 /$ jcs. 116855

Juretić, N., García-Huidobro, P., Iturrieta, J. A., Jaimovich, E., and Riveros, N. (2006). Depolarization-induced slow $\mathrm{Ca}^{2+}$ transients stimulate transcription of IL-6 gene in skeletal muscle cells. Am. J. Physiol. Cell Physiol. 290, C1428C1436. doi: 10.1152/ajpcell.00449.2005

Keller, P., Penkowa, M., Keller, C., Steensberg, A., Fischer, C. P., Giralt, M., et al. (2005). Interleukin-6 receptor expression in contracting human skeletal muscle: regulating role of IL-6. FASEB J. 19, 1181-1183. doi: 10.1096/fj.043278fje

Khairallah, R. J., Shi, G., Sbrana, F., Prosser, B. L., Borroto, C., Mazaitis, M. J., et al. (2012). Microtubules underlie dysfunction in duchenne muscular dystrophy. Sci. Signal. 5, ra56. doi: 10.1126/scisignal.2002829

Kirwan, J. P., Solomon, T. P. J., Wojta, D. M., Staten, M. A., and Holloszy, J. O. (2009). Effects of 7 days of exercise training on insulin sensitivity and responsiveness in type 2 diabetes mellitus. Am. J. Physiol. Endocrinol. Metab. 297, E151-E156. doi: 10.1152/ajpendo.00210.2009

Lambeth, J. D. (2004). NOX enzymes and the biology of reactive oxygen. Nat. Rev. Immunol. 4, 181-189. doi: 10.1038/nri1312

Larsen, S., Nielsen, J., Hansen, C. N., Nielsen, L. B., Wibrand, F., Stride, N., et al. (2012). Biomarkers of mitochondrial content in skeletal muscle of healthy young human subjects. J. Physiol. 590, 3349-3360. doi: 10.1113/jphysiol.2012.230185

Li, Q., Spencer, N. Y., Oakley, F. D., Buettner, G. R., and Engelhardt, J. F. (2009). Endosomal Nox2 facilitates redox-dependent induction of NF-kappaB by TNF-alpha. Antioxid. Redox Signal. 11, 1249-1263. doi: 10.1089/ars.2008. 2407

Libermann, T. A., and Baltimore, D. (1990). Activation of interleukin-6 gene expression through the NF-kappa B transcription factor. Mol. Cell. Biol. 10, 2327-2334. doi: 10.1128/MCB.10.5.2327

Michailidis, Y., Karagounis, L. G., Terzis, G., Jamurtas, A. Z., Spengos, K., Tsoukas, D., et al. (2013). Thiol-based antioxidant supplementation alters human skeletal muscle signaling and attenuates its inflammatory response and recovery after intense eccentric exercise. Am. J. Clin. Nutr. 98, 233-245. doi: 10.3945/ajcn.112.049163

Mofarrahi, M., Brandes, R. P., Gorlach, A., Hanze, J., Terada, L. S., Quinn, M. T., et al. (2008). Regulation of proliferation of skeletal muscle precursor cells by NADPH oxidase. Antioxid. Redox Signal. 10, 559-574. doi: 10.1089/ars.2007.1792

Neufer, P. D., Bamman, M. M., Muoio, D. M., Bouchard, C., Cooper, D. M., Goodpaster, B. H., et al. (2015). Understanding the cellular and molecular mechanisms of physical activity-induced health benefits. Cell Metab. 22, 4-11. doi: 10.1016/j.cmet.2015.05.011

Osman, A. A., Pendergrass, M., Koval, J., Maezono, K., Cusi, K., Pratipanawatr, T., et al. (2000). Regulation of MAP kinase pathway activity in vivo in human skeletal muscle. Am. J. Physiol. Endocrinol. Metab. 278, E992-E999.

Paulsen, G., Cumming, K. T., Holden, G., Hallén, J., Rønnestad, B. R., Sveen, O., et al. (2014a). Vitamin C and E supplementation hampers cellular adaptation to endurance training in humans: a double-blind, randomised, controlled trial. J. Physiol. 592, 1887-1901. doi: 10.1113/jphysiol.2013.267419

Paulsen, G., Hamarsland, H., Cumming, K. T., Johansen, R. E., Hulmi, J. J., Børsheim, E., et al. (2014b). Vitamin C and E supplementation alters protein signalling after a strength training session, but not muscle growth during 10 weeks of training. J. Physiol. 592, 5391-5408. doi: 10.1113/jphysiol.2014.2 79950

Pearson, T., Kabayo, T., Ng, R., Chamberlain, J., McArdle, A., and Jackson, M. J. (2014). Skeletal muscle contractions induce acute changes in cytosolic superoxide, but slower responses in mitochondrial superoxide and cellular hydrogen peroxide. PLoS ONE 9:e96378. doi: 10.1371/journal.pone.0096378

Pedersen, B. K., and Febbraio, M. A. (2012). Muscles, exercise and obesity: skeletal muscle as a secretory organ. Nat. Rev. Endocrinol. 8, 457-465. doi: 10.1038/nrendo.2012.49

Perry, C. G. R., Lally, J., Holloway, G. P., Heigenhauser, G. J. F., Bonen, A., and Spriet, L. L. (2010). Repeated transient mRNA bursts precede increases in transcriptional and mitochondrial proteins during training in human skeletal muscle. J. Physiol. 588, 4795-4810. doi: 10.1113/jphysiol.2010.199448

Petersen, A. C., McKenna, M. J., Medved, I., Murphy, K. T., Brown, M. J., Della Gatta, P., et al. (2012). Infusion with the antioxidant $\mathrm{N}$-acetylcysteine attenuates early adaptive responses to exercise in human skeletal muscle. Acta Physiol. (Oxf). 204, 382-392. doi: 10.1111/j.1748-1716.2011.02344.x

Piantadosi, C. A., and Suliman, H. B. (2012). Redox regulation of mitochondrial biogenesis. Free Radic. Biol. Med. 53, 2043-2053. doi: 10.1016/j.freeradbiomed.2012.09.014

Powers, S. K., Talbert, E. E., and Adhihetty, P. J. (2011). Reactive oxygen and nitrogen species as intracellular signals in skeletal muscle. J. Physiol. 589, 2129-2138. doi: 10.1113/jphysiol.2010.201327

Qi, Z., He, Q., Ji, L., and Ding, S. (2014). Antioxidant supplement inhibits skeletal muscle constitutive autophagy rather than fasting-induced autophagy in mice. Oxid. Med. Cell. Longev. 2014:315896. doi: 10.1155/2014/315896

Ristow, M., Zarse, K., Oberbach, A., Klöting, N., Birringer, M., Kiehntopf, M., et al. (2009). Antioxidants prevent health-promoting effects of physical exercise in humans. Proc. Natl. Acad. Sci. U.S.A. 106, 8665-8670. doi: 10.1073/pnas.0903485106

Sakellariou, G. K., Jackson, M. J., and Vasilaki, A. (2014). Redefining the major contributors to superoxide production in contracting skeletal muscle. The role of $\mathrm{NAD}(\mathrm{P}) \mathrm{H}$ oxidases. Free Radic. Res. 48, 12-29. doi: 10.3109/10715762.2013.830718

Sakellariou, G. K., Vasilaki, A., Palomero, J., Kayani, A., Zibrik, L., McArdle, A., et al. (2013). Studies of mitochondrial and nonmitochondrial sources implicate nicotinamide adenine dinucleotide phosphate oxidase(s) in the increased skeletal muscle superoxide generation that occurs during contractile activity. Antioxid. Redox Signal. 18, 603-621. doi: 10.1089/ars.2012.4623

Sánchez, G., Escobar, M., Pedrozo, Z., Macho, P., Domenech, R., Härtel, S., et al (2008). Exercise and tachycardia increase NADPH oxidase and ryanodine receptor-2 activity: possible role in cardioprotection. Cardiovasc. Res. 77, 380-386. doi: 10.1093/cvr/cvm011

Sano, M., and Fukuda, K. (2008). Activation of mitochondrial biogenesis by hormesis. Circ. Res. 103, 1191-1193. doi: 10.1161/CIRCRESAHA.108.189092

Scheele, C., Nielsen, S., and Pedersen, B. K. (2009). ROS and myokines promote muscle adaptation to exercise. Trends Endocrinol. Metab. 20, 95-99. doi: 10.1016/j.tem.2008.12.002

Steensberg, A., van Hall, G., Osada, T., Sacchetti, M., Saltin, B., and Klarlund Pedersen, B. (2000). Production of interleukin-6 in contracting human skeletal muscles can account for the exercise-induced increase in plasma interleukin-6. J. Physiol. 529(Pt 1), 237-242. doi: 10.1111/j.1469-7793.2000.00237.x

Strobel, N. A., Peake, J. M., Matsumoto, A., Marsh, S. A., Coombes, J. S., and Wadley, G. D. (2011). Antioxidant supplementation reduces skeletal muscle mitochondrial biogenesis. Med. Sci. Sports Exerc. 43, 1017-1024. doi: 10.1249/MSS.0b013e318203afa3 
Ushio-Fukai, M. (2006). Localizing NADPH oxidase-derived ROS. Sci. STKE 2006:re8. doi: 10.1126/stke.3492006re8

Valladares, D., Almarza, G., Contreras, A., Pavez, M., Buvinic, S., Jaimovich, E., et al. (2013). Electrical stimuli are anti-apoptotic in skeletal muscle via extracellular ATP. Alteration of this signal in Mdx mice is a likely cause of dystrophy. PLoS ONE 8:e75340. doi: 10.1371/journal.pone.0075340

Vejrazka, M., Mícek, R., and Stípek, S. (2005). Apocynin inhibits NADPH oxidase in phagocytes but stimulates ROS production in non-phagocytic cells. Biochim. Biophys. Acta 1722, 143-147. doi: 10.1016/j.bbagen.2004.12.008

Wadley, G. D., Nicolas, M. A., Hiam, D. S., and McConell, G. K. (2013). Xanthine oxidase inhibition attenuates skeletal muscle signaling following acute exercise but does not impair mitochondrial adaptations to endurance training. Am. J. Physiol. Endocrinol. Metab. 304, E853-E862. doi: 10.1152/ajpendo.00568.2012

Wang, Q., Wang, W., Wang, G., Rodney, G. G., and Wehrens, X. H. T. (2015). Crosstalk between RyR2 oxidation and phosphorylation contributes to cardiac dysfunction in mice with Duchenne muscular dystrophy. J. Mol. Cell. Cardiol. 89, 177-184. doi: 10.1016/j.yjmcc.2015.11.009

Yamacita-Borin, F. Y., Zarpelon, A. C., Pinho-Ribeiro, F. A., Fattori, V., AlvesFilho, J. C., Cunha, F. Q., et al. (2015). Superoxide anion-induced pain and inflammation depends on TNF $\alpha / T N F R 1$ signaling in mice. Neurosci. Lett. 605, 53-58. doi: 10.1016/j.neulet.2015.08.015

Yao, H., Yang, S.-R., Kode, A., Rajendrasozhan, S., Caito, S., Adenuga, D., et al. (2007). Redox regulation of lung inflammation: role of NADPH oxidase and NF-kappaB signalling. Biochem. Soc. Trans. 35, 1151-1155. doi: 10.1042/BST0351151
Yfanti, C., Fischer, C. P., Nielsen, S., Akerström, T., Nielsen, A. R., Veskoukis, A. S., et al. (2012). Role of vitamin C and E supplementation on IL-6 in response to training. J. Appl. Physiol. 112, 990-1000. doi: 10.1152/japplphysiol.01027. 2010

Yokota, T., Kinugawa, S., Hirabayashi, K., Matsushima, S., Inoue, N., Ohta, Y., et al. (2009). Oxidative stress in skeletal muscle impairs mitochondrial respiration and limits exercise capacity in type 2 diabetic mice. Am. J. Physiol. Heart Circ. Physiol. 297, H1069-H1077. doi: 10.1152/ajpheart.00267.2009

Zhu, X., Shen, K., Bai, Y., Zhang, A., Xia, Z., Chao, J., et al. (2016). $\mathrm{NADPH}$ oxidase activation is required for pentylenetetrazole kindlinginduced hippocampal autophagy. Free Radic. Biol. Med. 94, 230-242. doi: 10.1016/j.freeradbiomed.2016.03.004

Conflict of Interest Statement: The authors declare that the research was conducted in the absence of any commercial or financial relationships that could be construed as a potential conflict of interest.

Copyright () 2016 Henríquez-Olguín, Díaz-Vegas, Utreras-Mendoza, Campos, Arias-Calderón, Llanos, Contreras-Ferrat, Espinosa, Altamirano, Jaimovich and Valladares. This is an open-access article distributed under the terms of the Creative Commons Attribution License (CC BY). The use, distribution or reproduction in other forums is permitted, provided the original author(s) or licensor are credited and that the original publication in this journal is cited, in accordance with accepted academic practice. No use, distribution or reproduction is permitted which does not comply with these terms. 